\title{
Motion Artifact Reduction in Contrast-Enhanced Dual-Energy Mammography - A Multireader Study about the Effect of Nonrigid Registration as Motion Correction on Image Quality
}

\author{
Bewegungsartefakte in der kontrastverstärkten Dual-Energy \\ Mammografie - eine Multireader-Studie zur Wertigkeit \\ der nicht-rigiden Registrierung auf die Bildqualität
}

Authors

Markus Sistermanns ${ }^{10}$, Bernd Kowall ${ }^{2}$, Mathias Hörnig ${ }^{3}$, Karsten Beiderwellen ${ }^{1}$, Detlev Uhlenbrock ${ }^{1}$

Affiliations

1 Department of Radiology, MVZ Prof. Dr. Uhlenbrock \& Partner, Dortmund, Germany

2 Center of Clinical Epidemiology, Institute for Medical Informatics, Biometry and Epidemiology, Medical Faculty, University Duisburg-Essen, Germany

3 Department of Diagnostic imaging, X-ray Products, X-ray Physics \& Systems, Siemens Healthcare GmbH Forchheim, Germany

Key words

mammography, artifacts, breast, image processing

received 07.09 .2020

accepted 01.02.2021

published online 18.03.2021

Bibliography

Fortschr Röntgenstr 2021; 193: 1183-1188

DOI 10.1055/a-1388-7712

ISSN $1438-9029$

(c) 2021. Thieme. All rights reserved.

Georg Thieme Verlag KG, Rüdigerstraße 14,

70469 Stuttgart, Germany

Correspondence

Markus Sistermanns

Abteilung für Radiologie, MVZ Prof. Dr. Uhlenbrock \& Partner, Zollernstraße 40, 44379 Dortmund, Germany

Tel.: +49/2 31/9638608190

msistermanns@gmail.com

\section{ZUSAMMENFASSUNG}

Ziel Bewegungsartefakte werden bei der contrast-enhanced dual-energy mammografy (CEDEM) durch die technisch bedingte Verzögerung zwischen den Low- und High-energyAufnahmen begünstigt. In dieser Studie wurde die Wertigkeit einer Bewegungskorrektur durch unstarre Registrierung auf die Bildqualität der rekombinierten CEDEM-Bilder untersucht. Material und Methoden Retrospektiv wurde für 354 rekombinierte CEDEM-Bilder ein zusätzliches rekombiniertes Bild aus den Rohdaten der Low-energy- und High-energy-Aufnah- men mithilfe eines Bewegungskorrekturalgorithmus prozessiert. Fünf Radiologen mit langjähriger Erfahrung in der Brustkrebsdiagnostik verglichen im Side-by-side-Verfahren je ein durch den Standardalgorithmus prozessiertes CEDEM-Bild mit dem korrelierenden, durch den Bewegungskorrekturalgorithmus prozessierten CEDEM-Bild. Jedes Bilderpaar wurde anhand der folgenden 6 Kriterien verglichen: allgemeine Bildqualität (1), Hautkonturschärfe (2), Bildartefaktreduktion (3), Läsionskonturschärfe (4), Läsionskontrast (5), und Lymphknotensichtbarkeit (6). Die Kriterien wurden auf einer Likert-Skala bewertet (Verbesserung: + 1, + 2; Verschlechterung: $-1,-2)$.

Ergebnisse Die mittleren Bewertungen der Kriterien 1-5 zeigen eine Überlegenheit der mittels Bewegungskorrektur prozessierten rekombinierten CEDEM-Bilder. Beispielsweise liegt die mittlere Bewertung der allgemeinen Bildqualität bei 0,86 (95\%-KI 0,78-0,93). Lediglich die mittlere Bewertung von Kriterium 6 zeigt eine Unterlegenheit der mittels Bewegungskorrektur prozessierten rekombinierten CEDEM-Bilder (-0,29; $95 \%-K I-0,46$ bis $-0,13)$.

Schlussfolgerung Die Anwendung einer Bewegungskorrektur in Form einer unstarren Registrierung verbessert verschiedene Bildqualitätskriterien der rekombinierten CEDEM-Bilder, aber auf Kosten einer verschlechterten Lymphknotensichtbarkeit.

\section{Kernaussagen:}

- Die Nutzung der Bewegungskorrektur verbessert die Bildqualität.

- Die Bewegungskorrektur könnte das Potenzial haben, die diagnostische Genauigkeit zu erhöhen.

- Alternative Verfahren zur Bewegungsartefaktreduktion sind im klinischen Alltag aktuell nicht verfügbar.

\section{ABSTRACT}

Purpose The technically caused delay between low-energy (LE) and high-energy (HE) acquisitions allows motion artifacts in contrast-enhanced dual-energy mammography (CEDEM). In this study the effect of motion correction by nonrigid registration on image quality of the recombined images was investigated. 
Materials and Methods Retrospectively for 354 recombined CEDEM images an additional recombined image was processed from the raw data of LE and HE images using the motion correction algorithm. Five radiologists with many years of experience in breast cancer diagnostic imaging compared side-by-side one conventional processed CEDEM image with the corresponding image processed by the motion correction algorithm. Every pair of images was compared based on six criteria: General image quality (1), sharpness of skin contour (2), reduction of image artifacts (3), sharpness of lesion contour (4), contrast of lesion (5), visibility of lymph nodes (6). These criteria were rated on a Likert scale (improvement: +1 , + 2; deterioration: $-1,-2$ ).

Results The mean ratings concerning criteria 1-5 showed a superiority of the recombined images processed by the motion correction algorithm. For example, the mean rating of general image quality was 0.86 ( $95 \% \mathrm{Cl}: 0.78 ; 0.93)$. Only the mean rating concerning criterion 6 showed an inferiority of the recombined images processed by the motion correction algorithm $(-0.29(-0.46 ;-0.13))$.
Conclusion The usage of nonrigid registration for motion correction significantly improves the general image quality and the quality of subordinate criteria on the recombined CEDEM images at the expense of somewhat reduced lymph node visibility in some cases.

\section{Key Points:}

- The usage of motion correction in CEDEM improves the general image quality

- Motion correction might have the potential to increase diagnostic accuracy

- Alternative methods of motion artifact reduction are not yet available in clinical practice

\section{Citation Format}

- Sistermanns M, Kowall B, Hörnig M et al. Motion Artifact Reduction in Contrast-Enhanced Dual-Energy Mammography - A Multireader Study about the Effect of Nonrigid Registration as Motion Correction on Image Quality. Fortschr Röntgenstr 2021; 193: 1183-1188

\section{Introduction}

In many published studies concerning contrast-enhanced mammography, patient motion between the single image acquisitions is considered a source of image artifacts. Due to the increased acquisition time, this affects especially temporal subtraction contrast-enhanced mammography [1-5]. However, artifacts caused by motion between the acquisition of low-energy (LE) and highenergy (HE) images in contrast-enhanced dual-energy mammography (CEDEM) have also been described [3, 5-13]. On the one hand, artifacts have the potential to blur the borders of radiopaque structures [5, 6]. On the other hand, misregistration can possibly feign contrast enhancement in a region [11] or a contrast-enhancing lesion can be shown with a degraded density [12], which can both lead to misdiagnosis. Therefore, image artifacts caused by motion affect the image quality and possibly the diagnostic accuracy negatively. At best, usage of motion correction removes the negative effects. In this study for every conventional processed recombined CEDEM image, an additional motion-corrected recombined CEDEM image was processed from the raw data using an algorithm (Siemens Healthineers, Germany) which was implemented in our CEDEM system (MAMMOMAT Revelation, Siemens Healthineers, Germany). To assess the effect of motion correction on image quality, each conventional processed image was compared with the correlating motion-corrected image side-by-side.

To the best of our knowledge, an exact analysis and statistical assessment of the effect of motion correction in CEDEM has not yet been conducted in the course of other research.

The purpose of the study was to investigate the effect of the motion correction algorithm. This was accomplished by six image quality criteria and by demonstrating the superiority or inferiority among the differently processed images.

\section{Materials and Methods}

\section{Study design}

Retrospectively, for all performed CEDEM examinations in our institution from October 2017 to October 2019 with saved raw data, additional recombined images were processed from the LE and $\mathrm{HE}$ images using the motion correction algorithm. A total of 358 CEDEM examinations with saved raw data were performed in 93 patients (35-80 years; average age 56.5; standard deviation 10.12 ) in the diagnostic workup of mammography. Image material of all CEDEM examination with saved raw data was included. Special inclusion or exclusion criteria were not present. Written informed consent from all patients for further usage of the acquired image material was obtained. After consultation with the Institutional Review Board, we obtained confirmation that explicit approval was not required as no examination was performed for this study and the used data set was completely anonymized.

\section{Technique}

All CEDEM examinations were performed on a mammography system capable of CEDEM (MAMMOMAT Revelation with TiCEM option, Siemens Healthineers, Germany). Weight-adapted $(1.5 \mathrm{ml} / \mathrm{kg})$ intravenous application of lohexol at a rate of $3 \mathrm{ml} / \mathrm{s}$ using a power injector (CT motion ${ }^{\mathrm{TM}}$ XD 8000, Ulrich medical, Germany) was followed by intravenous application of $10 \mathrm{ml}$ of a physiologic saline solution. Two minutes after completed injection, image acquisition started, beginning with the suspicious breast in CC then MLO projection, followed by the contralateral breast in the same order. For 7 patients with the status post-mastectomy, just one breast was examined (5 left, 2 right). Dependent on breast thickness, the LE images were acquired between 23-32 kV. The HE images were acquired by using the system's 
specific titanium filter at $49 \mathrm{kV}$. The delay between LE and HE acquisition was about 10 seconds. For each of the 358 recombined CEDEM images, an algorithm (Siemens Healthineers, Germany) used the raw data to process an additional motion-corrected recombined image. The algorithm uses nonrigid registration. An iterative process was used to align the position of vasculature contours among LE and HE images. In this process, the LE image, which contains the morphological information, is used as a mask. The HE image will be adjusted accordingly by iteratively decreasing the misplacement between the two images. In cases without motion and consecutively an optimal overlap of LE and HE images, the algorithm would not apply a correction to the recombined image [14]. 4 of the 358 pairs of images were found to be corrupted during the reading phase and were removed from the evaluation. Therefore, 354 pairs of images were considered. Criteria 1, 2 and 3 were rated for $100 \%$ of pairs of images. Criteria 4 and 5 were rated for $17.7 \%$ and $17.6 \%$, respectively, and criterion 6 was rated for $13.5 \%$ of pairs of images, because these criteria were only given for some images.

\section{Image analysis}

Six criteria were compared for every pair of images: General image quality (1); sharpness of skin contour (2); reduction of image artifacts (3); sharpness of lesion contour (4); contrast of lesion (5); visibility of lymph nodes (6). Based on these criteria, every reader compared a recombined CEDEM image with the corresponding motion-corrected recombined CEDEM image and rated a possible difference. The results on a 5 -point Likert scale were saved as numeric values ( 2 = better, 1 = slightly better, $0=$ no difference, -1 = slightly worse, -2 = worse) and transmitted to Microsoft Office Excel ${ }^{\circledR}$ by software developed for this study. If lesions and/ or lymph nodes were not visible, criteria 4, 5, and/or 6 were not gathered for this pair of images. If more than one lesion was visible, the lesion with the highest quality difference between the two images was compared.

Five readers with 10 to 35 years of experience in mammography reading used a syngo. Breast Care Workstation (Siemens Healthineers, Germany) for side-by-side comparison of a conventionally processed CEDEM image and the corresponding CEDEM image which was processed by the motion correction algorithm. The order for all 354 pairs of images was randomized for every reader. Which of the two processed images was shown on the left or the right side of the monitor was also randomized for each reader. It was expected that, if a reader recognized the motion-corrected version with high confidence, the motion-corrected version would be preferred. To prevent this bias the readers got the information that the pairs of images show two differently processed motion corrected images.

\section{Statistical analysis}

For statistical analysis, the software SAS (SAS Institute Inc., Version 9.4) was used. Data were analyzed using a mixed model (procedure PROC GLIMMIX) calculated on 3 levels. The individual patient and the $\mathrm{X}$-ray projection were added to the model as random effects. Hereby, the mixed model compensated for the fact that there were several images of the same patients. By letting all
- Table 1 Comparison of two corresponding images (motion-corrected, not motion-corrected) with respect to six different criteria ${ }^{a}$.

- Tab. 1 Vergleich zweier korrespondierender Bilder (bewegungskorrigiert, nicht bewegungskorrigiert) hinsichtlich 6 verschiedener Kriterien ${ }^{\mathrm{a}}$.

\begin{tabular}{|c|c|c|}
\hline criterion & $\begin{array}{l}\mathrm{N} \\
\text { (number of } \\
\text { ratings) }\end{array}$ & $\begin{array}{l}\text { mean rating } \\
(95 \% \mathrm{Cl})\end{array}$ \\
\hline general image quality & 1770 & $0.86(0.78-0.93)$ \\
\hline $\begin{array}{l}\text { contour sharpness of the } \\
\text { skin }\end{array}$ & 1770 & $0.63(0.57-0.70)$ \\
\hline $\begin{array}{l}\text { reduction of image } \\
\text { artifacts }\end{array}$ & 1770 & $0.92(0.84-1.00)$ \\
\hline $\begin{array}{l}\text { contour sharpness of a } \\
\text { lesion }\end{array}$ & 314 & $0.37(0.26-0.48)$ \\
\hline contrast of a lesion & 311 & $0.22(0.11-0.32)$ \\
\hline visibility of lymph nodes & 239 & $-0.29(-0.46-0.13)$ \\
\hline \multicolumn{3}{|c|}{$\begin{array}{l}\text { For every pair of images, the conventional and corresponding motion- } \\
\text { corrected images are compared by } 5 \text { readers on a Likert scale with } \\
\text { respect to six different criteria. Ratings of } 1 \text { or } 2 \text { indicate a better } \\
\text { rating, while ratings of }-1 \text { or }-2 \text { indicate a worse rating of the motion- } \\
\text { corrected image. } \\
\text { Bei jedem Bilderpaar wurde das konventionelle und das zugehörige } \\
\text { bewegungskorrigierte Bild von } 5 \text { Readern auf einer Likert-Skala hin- } \\
\text { sichtlich } 6 \text { verschiedener Kriterien verglichen. Bewertungen mit } 1 \text { oder } \\
2 \text { bedeuten eine bessere, Bewertungen mit - } 1 \text { oder - } 2 \text { eine schlechtere } \\
\text { Bewertung des bewegungskorrigierten Bildes. }\end{array}$} \\
\hline
\end{tabular}

readers rate all pairs of images, we prevented clustering of the results. Therefore, it was not necessary to consider clustering of results in the mixed model. The results are in the form of mean ratings with $95 \%$ confidence intervals $(\mathrm{Cl})$.

\section{Results}

354 pairs of images from 93 patients were rated. For 9 patients (approx. 9.7\%), malignant findings were established and histologically proven: 6 invasive ductal carcinomas (2 G1, 1 G2 and 3 G3) and 3 invasive lobular carcinomas ( $1 \mathrm{G} 1$ and $2 \mathrm{G} 2$ ). For 22 patients (approx. 23.7\%) benign findings were established. The exact classifications were inaccessible due to the anonymous data set. For the other 62 patients, no lesion was found.

Criteria 1,2 , and 3 were rated by the readers for $100 \%$ of pairs of images $(N=1770)$. Criterion 4 was rated for $17.7 \%(N=314$, 63 pairs of images), criterion 5 for $17.6 \%(\mathrm{~N}=311,62$ pairs of images) and criterion 6 for $13.5 \%(N=239,48$ pairs of images $)$ of the 354 pairs of images by the readers. The discrepancy $N=3$ between criteria 4 and 5 results from one missing rating for readers 1,2 , and 3 .

The calculated results of the mean ratings including the $95 \% \mathrm{Cl}$ considering the random effects are shown in $>$ Table 1 . The mean ratings concerning criteria $1-5$ show a superiority of the recom- 
- Table 2 Comparison of the readers with respect to the criterion "general image quality"a.

- Tab.2 Vergleich der Reader hinsichtlich des Kriteriums „allgemeine Bildqualität“a.

\begin{tabular}{|c|c|c|c|c|c|c|}
\hline \multirow[t]{2}{*}{ reader } & \multicolumn{5}{|c|}{$\begin{array}{l}\text { ratings on the likert scale } \\
n(\%)\end{array}$} & \multirow[t]{2}{*}{$\begin{array}{l}\text { mean rating } \\
(95 \% \mathrm{Cl})\end{array}$} \\
\hline & -2 & -1 & 0 & 1 & 2 & \\
\hline 1 & $3(0.9)$ & $34(9.6)$ & $18(5.1)$ & $226(63.8)$ & $73(20.6)$ & $0.94(0.83-1.04)$ \\
\hline 2 & $1(0.3)$ & $22(6.2)$ & 45 (12.7) & $201(56.8)$ & $85(24.0)$ & $0.98(0.89-1.08)$ \\
\hline 3 & $4(1.1)$ & $10(2.8)$ & 42 (11.9) & $108(30.5)$ & $190(53.7)$ & $1.32(1.21-1.44)$ \\
\hline 4 & $6(1.7)$ & $7(2.0)$ & $68(19.2)$ & $174(49.2)$ & $99(28.0)$ & $1.00(0.89-1.10)$ \\
\hline 5 & 0 & $113(31.9)$ & $114(32.2)$ & 127 (35.9) & 0 & $0.04(-0.05-0.13)$ \\
\hline
\end{tabular}

bined images processed by the motion correction algorithm. For instance, the mean rating of the general image quality is 0.86 ( $95 \% \mathrm{Cl}: 0.78 ; 0.93)$. Only the mean rating of the criterion "visibility of lymph nodes" shows an inferiority of the recombined images processed by the motion correction algorithm $(-0.29(-0.46$; $-0.13)$ ).

- Table 2 describes the results of the superior criterion "general image quality" (criterion 1) based on the ratings of the individual readers. The calculated results of the mean ratings including the $95 \% \mathrm{Cl}$ considering the random effects are shown. Readers 14 rated the general image quality as better after motion correction. Only reader 5 rated the general image quality for both recombination processes as equal. For criteria 2-5, the pattern was the same, i. e., reader 5 gave worse ratings for the motion-corrected images than readers 1-4 (data not shown). The modal value of ratings was +1 for all readers except for reader 3 , for whom the modal value was +2 . The only reader who did not use the extreme ratings +2 and -2 was reader 5 .

The mean ratings including the $95 \% \mathrm{Cl}$ of readers $1-4$ for the general image quality are $>0$ and show significant superiority of the motion-corrected images. The mean rating including the $95 \% \mathrm{Cl}$ of reader 5 for this criterion is 0.04 (95\% Cl: $-0.05-0.13$ ), around 0 , indicating no significant difference in the quality of the compared images.

\section{Conclusion and Discussion}

The objective of the study was to assess the effect of motion correction in CEDEM on image quality. For the criteria general image quality (1), sharpness of skin contour (2), and reduction of image artifacts (3), clear superiority of the motion-corrected images was shown. For the criteria sharpness of lesion contour (4) and contrast of lesion (5), moderate superiority of the motion-corrected images was shown ( $\bullet$ Fig. 1 ).

For the criterion visibility of lymph nodes (6), moderate inferiority of the motion-corrected images was shown ( $\triangleright$ Fig. 2).
This leads to the conclusion that motion-corrected processing in CEDEM can improve image quality and reduce general image artifacts. Reduced lymph node visibility on the recombined images caused by the motion-corrected processing appears to be an acceptable deterioration, because the lymph node visibility on the FFDM and the LE images - which are always available in clinical practice - is not reduced. It must be mentioned that the contrast uptake of lymph nodes varies depending on tissue composition and lymph node status. For instance, a fully fatty involuted lymph node is not expected to show significant contrast uptake and should therefore not be visible on the recombined images.

The ratings of reader 5 for criterion 1 ( $\vee$ Table 2 ), which differ from those of the other readers, are worthy of discussion. Reader 5 shows a clear tendency toward conservative evaluation. The extreme ratings $(+2,-2)$ were not used by reader 5 . Furthermore, this reader used the rating 0 by far the most of all readers. This rating behavior is most likely caused by the fact that in the vast majority of the cases motion correction led to better image quality but did not profoundly influence the reading of the image. In no case were the noticeable motion artifacts the reason for incorrect diagnosis or an overlooked cancer. Moreover, the contrast and delineation of all enhancing cancers were only barely or not substantially influenced by the motion correction. Therefore, grading the difference of the corrected and non-corrected images with 0 is justified but not mandatory. The better impression of the images with motion correction justifies the rating +1 or +2 in the same way.

General recommendations in the literature for the reduction of motion artifacts in CEDEM describe the need to tell the patients that they must not move and to use adequate compression during the examination $[5,6,15]$. Individual previous studies described the use of spectral detectors that were able to acquire the LE and $\mathrm{HE}$ images simultaneously and thus lead to complete elimination of motion artifacts between LE and HE acquisition [15, 16]. However, these studies used phantoms for imaging and these technologies are not yet available in clinical practice. In breast MRI nonrigid registration is a well-known method for the compen- 


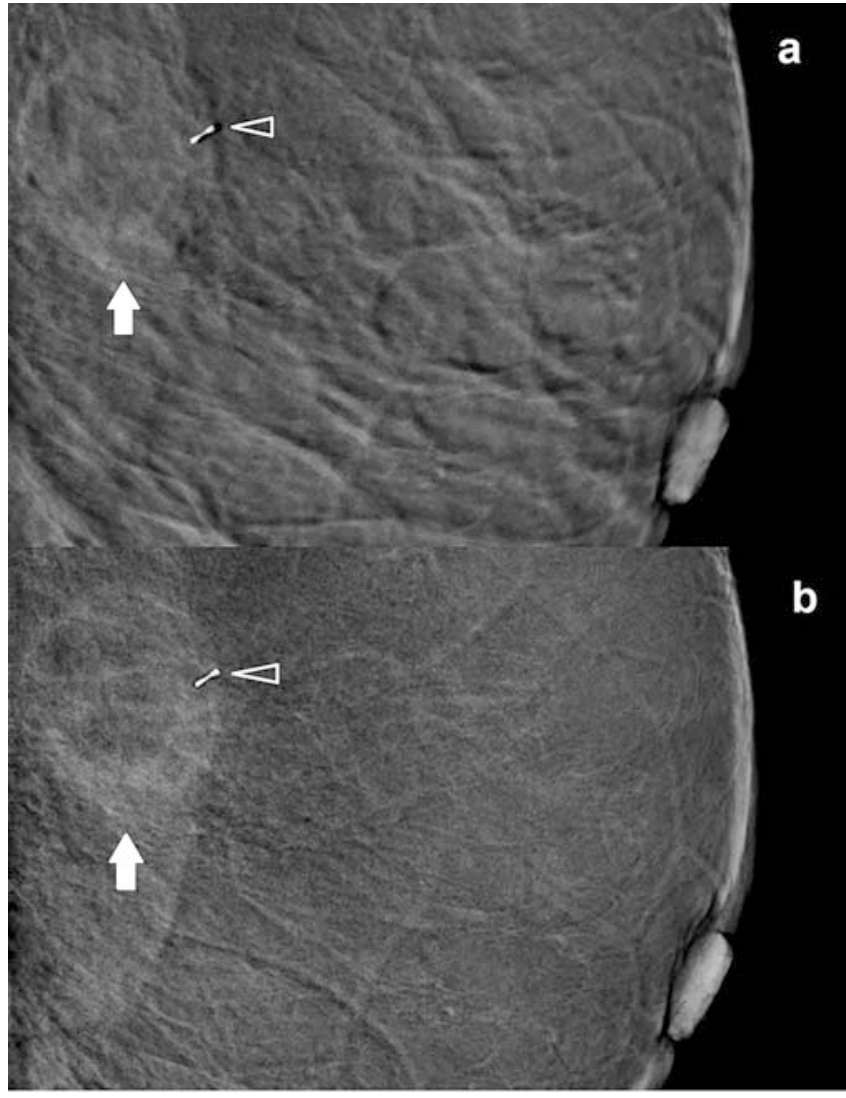

- Fig. 1 Magnified section of recombined CEDEM images of the left breast in MLO projection. Histologically proven invasive ductal carcinoma (G3) (arrow). a Image processed by conventional recombination. Contours of lesion (arrow) and skin are blurred by motion. Misregistration of the clip with displaced black artifact (arrowhead). Inhomogeneous imaging of the subtracted background parenchyma. $\mathbf{b}$ Image processed by motion corrected recombination. The visible iodine uptake in the lesion appears improved. The contour of the skin is sharper. The artifact caused by misregistration next to the clip (arrowhead) can no longer be recognized. The subtracted background parenchyma appears homogeneous.

- Abb. 1 Ausschnittvergrößerung von rekombinierten CEDEMBildern der linken Brust im MLO-Strahlengang. Bioptisch gesichertes invasives duktales Karzinom (G3) (Pfeil). a Mittels Standardverfahren prozessiertes Bild. Durch Bewegung ist die Kontur von Läsion (Pfeil) und Haut unschärfer. Fehlregistrierung des Clips mit versetztem schwarzem Artefakt (Pfeilspitze). Inhomogene Darstellung des subtrahierten Hintergrundparenchyms. b Mittels Bewegungskorrektur prozessiertes Bild. Die sichtbare Jodanreicherung in der Läsion (Pfeil) erscheint verbessert. Die Hautkontur erscheint schärfer. Das Artefakt durch Fehlregistrierung neben dem Clip (Pfeilspitze) ist nicht mehr abzugrenzen. Das subtrahierte Hintergrundparenchym erscheint homogen.

sation of motion-related changes [17]. In CEDEM the usage of nonrigid registration for the compensation of motion has only been sporadically described $[9,18]$. This study pursued this ap-

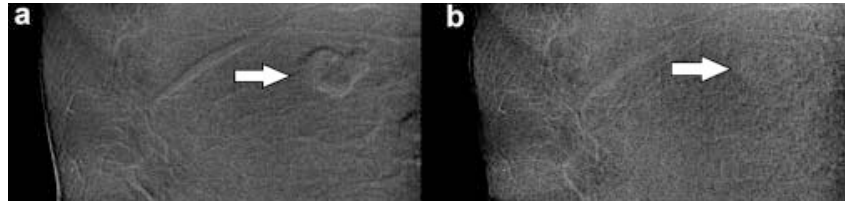

- Fig. 2 Visibility of lymph nodes. Magnified section of the right axilla on recombined CEDEM images of the right breast in MLO projection. a Image processed by conventional recombination. The contour of the lymph node (arrow) is recognizable. $\mathbf{b}$ Image processed by motion corrected recombination. The lymph node (arrow) is difficult to distinguish from the surrounding tissue.

- Abb. 2 Lymphknotensichtbarkeit. Ausschnittvergrößerung der rechten Axilla von rekombinierten CEDEM-Bildern der rechten Brust im MLO-Strahlengang. a Mittels Standardverfahren prozessiertes Bild. Die Kontur des Lymphknotens (Pfeil) ist gut erkennbar. b Mittels Bewegungskorrektur prozessiertes Bild. Der Lymphknoten (Pfeil) ist kaum vom umgebenden Gewebe zu differenzieren.

proach and showed the potential benefits of nonrigid registration in CEDEM. The results of the study show the relevance of motioncorrected processing of CEDEM in clinical practice but should not be overestimated. In the end the visibility of relevant findings is crucial and their qualitative presentation is only secondary. Only slight improvements in the decisive criteria sharpness of lesion contour (4) and contrast of lesion (5) were shown. It is questionable whether this affects the assessment of a lesion in clinical practice. Although there was no such case in this study, the blurring of existing [12] lesions and possible feigning of non-existent lesions [11] are described and conceivable in the case of marked motion artifacts. Motion-corrected processing might make it possible to minimize unnecessary further diagnostic uncertainty as well as false-negative findings. This might lead to lower costs and fewer additional procedures for patients, like MRI or ultrasound-guided biopsy. The algorithm is already integrated into the used mammography system and can be optionally activated. With usage of the motion correction algorithm in clinical practice, no additional effort is required and there is no significant delay in image processing.

A crucial limitation of the study was that just image quality criteria were assessed. The extent to which the improvement of the image quality in CEDEM influences the diagnostic accuracy was not investigated. This should be assessed in further studies. Another limitation of the study was the rough characterization of the subject population caused by the anonymization of the data set in which just the malignant lesions were available. Furthermore, lesions were visible only on $17.7 \%$ and lymph nodes only on $13.5 \%$ of the pairs of images, which is why criteria 4-6 had a lower number of ratings than criteria 1-3.

All in all, the usage of nonrigid registration for motion correction significantly improves general image quality and the quality of subordinate criteria on the recombined CEDEM images at the expense of a somewhat reduced lymph node visibility in some cases. 


\section{CLINICAL RELEVANCE OF THE STUDY}

- Non-rigid registration might have the potential to increase diagnostic accuracy.

- Non-rigid registration improves general image quality.

- Non-rigid registration might have the potential to minimize unnecessary further diagnostic procedures

\section{Funding}

Siemens Healthineers

\section{Conflict of Interest}

The MVZ Prof. Dr. Uhlenbrock \& Partner has received research support from Siemens Healthineers within the last 3 years.

Mathias Hörnig is employed by Siemens Healthineers.

The MVZ Prof. Dr. Uhlenbrock \& Partner has received research support from $A B-C T$ GmbH for the nu:view CT within the past 3 years.

\section{References}

[1] Daniaux M, de Zordo T, Santner W et al. Dual-energy contrast-enhanced spectral mammography (CESM). Archives of gynecology and obstetrics 2015; 292: 739-747

[2] Diekmann F, Diekmann S, Taupitz M et al. Use of iodine-based contrast media in digital full-field mammography-initial experience. RoFo: Fortschritte auf dem Gebiete der Rontgenstrahlen und der Nuklearmedizin 2003; 175: 342-345

[3] Dromain C, Thibault F, Muller $S$ et al. Dual-energy contrast-enhanced digital mammography: initial clinical results. European radiology 2011; 21: $565-574$

[4] Łuczyńska E, Heinze-Paluchowska S, Hendrick E et al. Comparison between breast MRI and contrast-enhanced spectral mammography. Medical science monitor: international medical journal of experimental and clinical research 2015; 21: 1358-1367

[5] Nori J, Gill MK, Vignoli C et al. Artefacts in contrast enhanced digital mammography: how can they affect diagnostic image quality and confuse clinical diagnosis? Insights into imaging 2020; 11: 16
[6] Nori ], Kaur M. Contrast-Enhanced Digital Mammography (CEDM). Cham: Springer International Publishing; 2018

[7] Bhimani C, Li L, Liao L et al. Contrast-enhanced Spectral Mammography: Modality-Specific Artifacts and Other Factors Which May Interfere with Image Quality. Academic radiology 2017; 24: 89-94

[8] Jochelson MS, Dershaw DD, Sung JS et al. Bilateral contrast-enhanced dual-energy digital mammography: feasibility and comparison with conventional digital mammography and MR imaging in women with known breast carcinoma. Radiology 2013; 266: 743-751

[9] Knogler T, Homolka P, Hörnig M et al. Contrast-enhanced dual energy mammography with a novel anode/filter combination and artifact reduction: a feasibility study. European radiology 2016; 26: 1575-1581

[10] Lobbes MBI, Smidt ML, Houwers J et al. Contrast enhanced mammography: techniques, current results, and potential indications. Clinical radiology 2013; 68: 935-944

[11] Jong RA, Yaffe MJ, Skarpathiotakis M et al. Contrast-enhanced digital mammography: initial clinical experience. Radiology 2003; 228: 842850

[12] Badr S, Laurent N, Régis C et al. Dual-energy contrast-enhanced digital mammography in routine clinical practice in 2013. Diagnostic and interventional imaging 2014; 95: 245-258

[13] Yagil Y, Shalmon A, Rundstein A et al. Challenges in contrast-enhanced spectral mammography interpretation: artefacts lexicon. Clinical radiology 2016; 71: 450-457

[14] Biniazan R. Image Processing and physics of Dual Energy Contrast Enhanced Mammography (Master's Thesis). Erlangen-Nürnberg: FriedrichAlexander-Universität Erlangen-Nürnberg; 2017

[15] March LM. Hyperspectral X-ray Imaging: A comparison of iodinated and gold nanoparticle contrast media for the application of contrast-enhanced digital mammography (Doctor's Thesis). Surrey: University of Surrey; 2018

[16] Pani S, Saifuddin SC, Ferreira FIM et al. High Energy Resolution Hyperspectral X-Ray Imaging for Low-Dose Contrast-Enhanced Digital Mammography. IEEE transactions on medical imaging 2017; 36: 1784-1795

[17] Rueckert D, Sonoda LI, Hayes C et al. Nonrigid registration using freeform deformations: application to breast MR images. IEEE transactions on medical imaging 1999; 18: 712-721

[18] Knogler T, Homolka P, Hoernig M et al. Application of BI-RADS Descriptors in Contrast-Enhanced Dual-Energy Mammography: Comparison with MRI. Breast care (Basel, Switzerland) 2017; 12: 212-216 